\title{
Meningkatkan Minat Mengartikan Sifat Mustahil Allah dengan Model Pembelajaran Make A Match
}

\section{Apri Tyas Rahmawati}

\author{
SDN 1 Tegalharjo \\ aprityas.at@gmail.com
}

\section{Article History \\ accepted 01/02/2020}

\begin{abstract}
This research aims to increase interest and learning outcomes in interpreting the impossible nature for God. The subjects of the study were grade 3 students of SDN 1 Tegalharjo in the $2017 / 2018$ academic year consisting of 18 students. This research is a classroom action research (CAR) consisting of two cycles for four months. Research data obtained from documentation, observation, tests, and interviews. The results of the study in cycle 1 showed that students who had very high interest 1, a high number of 9 students, in cycle 2 students who had very high interest were 14 students, high interest were 4 students. The results of the study of learning outcomes in cycle 1 students got grades with a very good predicate with a percentage of $16.67 \%$, grades with good categories with a percentage of $22.22 \%$, students got grades with enough categories with a percentage of $5.55 \%$, who got less grades with the percentage of $55.56 \%$. Classical completeness is $44.44 \%$. In cycle 2 students who scored very well with a percentage of $27.78 \%$, a good category with a percentage of $5.55 \%$, a sufficient category with a percentage of $66.67 \%$. Classical completeness by $100 \%$, has reached the target of research completeness by $80 \%$.
\end{abstract}

Keywords: interest, study, make a match

\begin{abstract}
Abstrak
Penelitian ini bertujuan untuk meningkatkan minat dan hasil belajar dalam mengartikan sifat mustahil bagi Allah. Subjek penelitian adalah siswa kelas 3 SDN 1 Tegalharjo Tahun Pelajaran 2017/2018 yang terdiri atas 18 siswa. Penelitian ini merupakan penelitian tindakan kelas (PTK) yang terdiri atas dua siklus selama empat bulan. Data penelitian diperoleh dari dokumentasi, observasi, tes, dan wawancara. Hasil penelitian pada siklus 1 menunjukkan bahwa siswa yang memiliki minat sangat tinggi 1, tinggi sejumlah 9 siswa, pada siklus 2 siswa yang memiliki minat sangat tinggi sebanyak 14 siswa, minat tinggi sebanyak 4 siswa. Hasil penelitian hasil belajar pada siklus 1 siswa mendapat nilai dengan predikat sangat baik dengan prosentase 16,67\%, nilai dengan kategori baik dengan prosentase $22,22 \%$, siswa mendapat nilai dengan kategori cukup dengan prosentase $5,55 \%$, yang mendapat nilai kurang dengan prosentase $55,56 \%$. Ketuntasan klasikal sebesar $44,44 \%$. Pada siklus 2 siswa yang mendapat nilai sangat baik dengan prosentase $27,78 \%$, kategori baik dengan prosentase $5,55 \%$, kategori cukup dengan prosentase $66,67 \%$. Ketuntasan klasikal sebesar $100 \%$, sudah mencapai target ketuntasan penelitian sebesar $80 \%$.
\end{abstract}

Kata kunci: minat, belajar, make a match 


\section{PENDAHULUAN}

Perkembangan jaman dan pesatnya teknologi sudah tidak dapat dipungkiri lagi. Dengan teknologi yang berkembang pesat seperti saat ini, memudahkan informasi sampai kepada semua orang. Teknologi informasi sudah sangat akrab di masyarakat tua maupun muda bahkan anak kecil. Teknologi informasi membawa dampak yang positif dan tak jarang membawa dampak yang negatif pula. Dampak negatif bisa timbul lebih besar jika anak-anak sudah sangat bebas mendapatkan akses informasi melalui teknologi yang akrab kita kenal dengan "medsos". Iman yang kuat sebagai benteng kita dari hal-hal yang negatif tersebut. Keimanan dan ketaqwaan harus kita tanamkan kepada generasi muda khususnya anak-anak. Sebagai seorang Islam khususnya, pendidikan agama islam harus kita terapkan sejak kecil agar bisa menjadi dasar dalam meniti setiap langkah dalam hidupnya di kemudian hari.

Pendidikan Agama Islam adalah usaha-usaha secara sistematis dan pragmatis dalam membantu anak didik agar mereka hidup sesuai dengan ajaran Islam (Zuhairani, 1983 : 27). Pendidikan agama islam adalah suatu usaha untuk membina dan mengasuh peserta didik agar senantiasa dapat memahami ajaran Islam secara menyeluruh, menghayati tujuan dan akhirnya dapat mengamalkan serta menjadikan Islam sebagai pandangan hidup (Zakiyah Daradjat, 1982)

Mata Pelajaran Pendidikan Agama Islam (PAI) di Sekolah Dasar (SD) secara keseluruhan berada pada lingkup AI Quran dan Al-Hadist, aqidah, fiqih, dan sejarah Islam. Ruang lingkup pendidikan agama Islam mencakup perwujudan keserasian, keselarasan dan keseimbangan hubungan manusia dengan Allah SWT, diri sendiri, sesama manusia, makhluk lainnya maupun lingkungannya (Hablun minallah wa hablun minannas). Jadi pendidikan agama Islam merupakan usaha sadar yang dilakukan pendidik dalam rangka mempersiapkan peserta didik untuk meyakini, memahami,dan mengamalkan ajaran Islam melalui kegiatan bimbingan, pengajaran atau pelatihan yang telah ditentukan untuk mencapai tujuan yang telah ditetapkan.

Rukun Iman menjadi salah satu dasar dalam beragama Islam dengan meyakini dengan sepenuh hati dan menghayatinya. Rukun Iman ada enam, yaitu: pertama iman kepada Allah SWT, kedua Iman kepada Malaikat, ketiga Iman kepada Kitab Allah SWT keempat iman kepada Rasul Allah SWT, kelima iman kepada Hari Kiamat, dan keenam kepada Qodho dan Qodar Allah SWT. Iman kepada Allah yaitu meyakini keberadaan Allah sebagai Tuhan yang telah menciptakan makhluk. Ada beberapa hal yang dapat dilakukan untuk mengimani keberadaan Allah dengan melihat alam semesta, dengan mengenal sifat-sifatNya dan dengan membaca Al Quran.

Sifat Allah ada tiga, yaitu sifat wajib, sifat mustahil, dan sifat jaiz Allah. Sifat mustahil bagi Allah adalah sifat-sifat yang tidak mungkin dimiliki Allah. Mengartikan sifat mustahil bagi Allah swt, tertera di Silabus Pendidikan Agama Islam tingkat SD kelas 3 pada semester 2. Yang berarti anak-anak memang harus dapat memahami arti sifat mustahil tersebut.

Namun pada kenyataannya anak-anak masih banyak yang sulit untuk mengartikan sifat mustahil Allah swt tersebut. Hal ini terlihat dari hasil pengamatan penulis yang sudah dilakukan di SD Negeri 1 Tegalharjo.

Proses pembelajaran pun terlihat kurang lancar jika dilihat minat siswa yang rendah, masih ada yang bermain sendiri, masih ada anak yang berjalan keliling kelas, serta hasil belajar rata-rata jauh di bawah KKM.

Melihat kesenjangan tersebut maka perlu dilakukan penelitian. Penelitian ini diharapkan dapat meningkatkan minat belajar dan kemampuan untuk menyebutkan lima sifat mustahil bagi Allah. Dapat menyebutkan secara baik dan benar sifat mustahil bagi Allah dan artinya. 


\section{METODE}

Pendekatan penelitian yang dilakukan dalam artikel ini adalah mixed method, yaitu gabungan antara pendekatan kualitatif dan pendekatan kuantitatif. Pendekatan kualitatif digunakan untuk mengukur minat siswa, sedang pendekatan kuantitatif untuk mengukur hasil belajar siswa.

Pendekatan kualitatif dilakukan dengan metode observasi dan wawancara sedangkan pendekatan kuantitatif dilakukan dengan tes tulis. Pendekatan penelitian yang dilakukan dalam artikel ini adalah mixed method, yaitu gabungan antara pendekatan kualitatif dan pendekatan kuantitatif. Pendekatan kualitatif digunakan untuk mengukur minat siswa, sedang pendekatan kuantitatif untuk mengukur hasil belajar siswa. Pendekatan kualitatif dilakukan dengan metode observasi dan wawancara sedangkan pendekatan kuantitatif dilakukan dengan tes tulis.

Subjek penelitian ini adalah siswa kelas III SD Negeri 1 Tegalharjo, Kecamatan Eromoko, Kabupaten Wonogiri. Jumlah siswa yang diteliti 18 siswa, terdiri dari 11 siswa putra dan 7 siswa putri. Siswa di kelas ini memiliki kemampuan rata-rata atau sedang, tidak ada yang menonjol. Dipilihnya kelas ini sebagai tempat penelitian karena dipandang ada potensi-potensi siswa yang belum muncul. Penulis bertindak sebagai peneliti. Sebagai kolabolator peneliti bekerjasama dengan guru kelas III. Objek penelitian adalah minat dan hasil belajar mengartikan sifat mustahil Allah.

Penelitian dilaksanakan selama empat bulan yaitu bulan Maret, April, Mei dan Juni 2018. Kegiatan-kegiatan dalam rentang waktu tersebut mencakup persiapan, pelaksanaan tindakan, hingga penyelesaian. Penelitian direncanakan menggunakan tindakan daur ulang seperti yang dikembangkan oleh Kemmis,S dan Mc.Taggart, $R$ (1988:20) dengan menggunakan langkah-langkah sebagai berikut : perencanaan, pelaksanaan, pengamatan dan refleksi. Dalam penelitian ini, dilaksanakan dalam dua siklus, Selanjutnya pelaksanaan tindakan digambarkan sebagai berikut

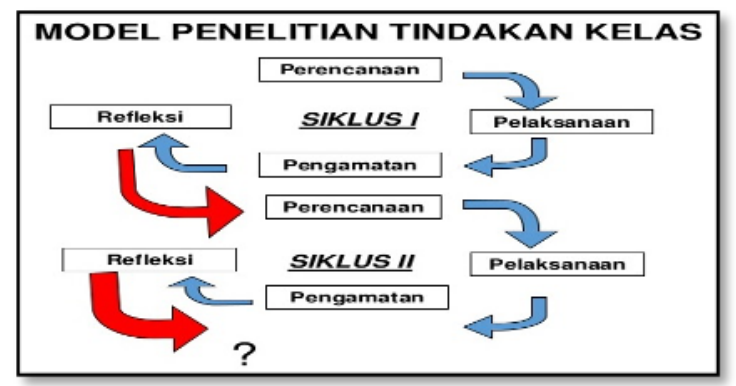

Gambar 1: Proses Perencanaan Penelitian dari Siklus 1 sampai dengan siklus 2

Data yang digunakan dalam penelitian ini, dikumpulkan melalui dokumentasi, observasi, tes, dan wawancara. Dokumen yang digunakan berupa skor penilaian sebelum dan sesudah menggunakan model pembelajaran make a match pada materi mengartikan sifat mustahil Allah dan foto-foto pelaksanaan pembelajaran di kelas.

Observasi yaitu mengumpulkan data dengan mengamati minat siswa dalam mengartikan sifat mustahil Allah pada prasiklus, siklus I dan siklus II. Tes berupa soal tertulis mengenai mengartikan sifat mustahil Allah, untuk mengetahui hasil belajar.

Wawancara dilakukan kepada beberapa anak didik untuk mengetahui besarnya minat belajar siswa dalam mengartikan sifat mustahil bagi Allah swt, sebelum dan sesudah menggunakan model pembelajaran make a match. Data pendukung penelitian yang akurat harus bersifat otentik dan dapat dipertanggungjawabkan kebenarannya. Untuk memperoleh data diperlukan alat pengumpulan data berupa: 
1. Dokumen yang berupa catatan tentang minat dan hasil belajar dalam mengartikan sifat mustahil Allah siswa pada prasiklus.

2. Lembar observasi berupa lembar pengamatan tentang minat dalam mengartikan sifat mustahil Allah pada setiap siklus.

3. Butir soal untuk tes tertulis tentang hasil belajar dalam mengartikan sifat mustahil Allah siswa pada setiap siklus.

4. Wawancara berupa catatan pertanyaan kepada siswa untuk menggali minat belajar anak.

5. Kriteria pengamatan untuk mengambil data minat siswa tentang Mengartikan sifat mustahil Allah sebagai berikut :

a. Tertarik kepada guru atau mata pelajarannya. ( Skor 1-5)

b. Selalu ingin terlibat dalam setiap kegiatan. (Skor 1-5)

c. Mengulang pelajaran yang telah diberikan. ( Skor 1-5)

d. Kecenderungan yang tinggi untuk tetap memperhatikan. ( Skor 1-5)

e. Tidak mudah bosan. ( Skor $1-5$ )

Target yang diharapkan dalam hasil belajar siswa tentang Mengartikan sifat mustahil Allah adalah dari rata - rata kurang pada kondisi awal, pada akhir siklus (akhir siklus 2 ) diharapkan meningkat menjadi; Rata - rata kelas dengan nilai tes 75 ; Target ke.tuntasan klasikal minimal mencapai $80 \%$ dengan KKM 70.

\section{HASIL DAN PEMBAHASAN}

Data prasiklus menunjukkan rata-rata skor minat belajar 12,94 masih terdapat siswa yang memiliki minat sedang dan rendah. Lebih jelasnya dapat dilihat dalam tabel 1 distribusi minat siswa prasiklus.

Berdasarkan tabel distribusi minat siswa di bawah dapat dikatakan tidak ada siswa yang memiliki minat sangat rendah. Terdapat 4 siswa yang memiliki minat rendah, 11 siswa memiliki minat sedang, 3 siswa memiliki minat belajar tinggi, dan tidak ada siswa yang memiliki minat yang sangat tinggi.

Tabel 1:Distribusi Minat Siswa Prasiklus

\begin{tabular}{|c|c|c|c|}
\hline No & Rentang Nilai & Frekuensi & Keterangan \\
\hline 1 & $21-25$ & 0 & Sangat tinggi \\
\hline 2 & $16-20$ & 3 & Tinggi \\
\hline 3 & $11-15$ & 11 & Sedang \\
\hline 4 & $6-10$ & 4 & Sangat rendah \\
\hline 5 & $\leq 5$ & 0 & \\
\hline
\end{tabular}

Minat anak dalam proses belajar mengartikan sifat mustahil Allah baru 3 anak yang memiliki minat yang tinggi, tentunya akan berpengaruh dalam hasil belajar. Pada siklus pertama ada peningkatan minat siswa dalam mempelajari sifat mustahil Allah dengan metode make a match walaupun secara kelompok. Setiap kelompok terlihat bekerja secara kompak walaupun masih ada yang belum ikut terlibat. Seperti yang terlihat pada tabel 2. 
Berdasarkan data hasil pengamatan observasi dapat dianalisis sebagai berikut:

a. Ketertarikan siswa kepada guru atau mata pelajaran sebesar $58,89 \%$

b. Keterlibatan siswa dalam kegiatan pembelajaran sebesar $68,89 \%$

c. Mengulang pelajaran sebesar $60 \%$

d. Perhatian siswa sebesar $65,56 \%$

e. Rasa tidak bosan siswa sebesar $62,22 \%$

Pada siklus 1 diperoleh hasil pengamatan minat anak dengan kategori minimal tinggi sebanyak 9 tinggi dan 1 sangat tinggi. Masih ada siswa yang memiliki minat yang sedang. Hasil distribusi minat siswa dalam pembelajaran selengkapnya dapat dilihat dalam tabel dibawah ini.

Tabel 3: Distribusi Minat siswa Siklus 1

\begin{tabular}{|c|c|c|c|}
\hline No & Rentang Nilai & Frekuensi & Keterangan \\
\hline 1 & $21-25$ & 1 & Sangat tinggi \\
\hline 2 & $16-20$ & 9 & Tinggi \\
\hline 3 & $11-15$ & 8 & Sedang \\
\hline 4 & $6-10$ & 0 & Rendah \\
\hline 5 & $\leq 5$ & 0 & Sangat rendah \\
\hline
\end{tabular}

Pada siklus 2 terlihat sudah tidak ada siswa yang memiliki minat yang dibawah 16. Semua siswa sudah memiliki nilai pengamatan minat minim dalam kategori tinggi, hasil observasi dapat dilihat pada tabel 4. Untuk lebih jelasnya dapat dilihat dalam tabel distribusi minat di bawah ini.

Tabel 5:Distribusi Minat Siswa Siklus 2

\begin{tabular}{|c|c|c|c|}
\hline No & $\begin{array}{c}\text { Rentang } \\
\text { Nilai }\end{array}$ & Frekuensi & Keterangan \\
\hline 1 & $21-25$ & 14 & Sangat tinggi \\
\hline 2 & $16-20$ & 4 & Tinggi \\
\hline 3 & $11-15$ & 0 & Sedang \\
\hline 4 & $5-10$ & 0 & Rendah \\
\hline
\end{tabular}

Siswa yang memiliki minat sangat tinggi sebanyak 14, yang memiliki minat tinggi sebanyak 4 . Sudah tidak ada siswa yang memiliki nilai pengamatan di bawah angka 16. Target penelitian minimal nilai pengamatan minat antara 16-20 atau kategori tinggi telah tercapai.

Tabel 2

Hasil Observasi Penilaian Minat Siswa pada Siklus 1

\begin{tabular}{|c|c|c|c|c|c|c|c|c|c|}
\hline \multirow{2}{*}{ No } & \multirow{2}{*}{ Responden } & \multicolumn{5}{|c|}{ Aspek Observasi } & \multirow{2}{*}{$\begin{array}{c}\text { Jumlah } \\
\text { Skor }\end{array}$} & \multirow{2}{*}{ Kategori } & \\
\hline & & 1 & 2 & 3 & 4 & 5 & & & \\
\hline 1 & Responden 1 & 3 & 3 & 3 & 4 & 4 & 17 & $T$ & \multirow{3}{*}{$\begin{array}{l}\text { 1. Ketertarikan } \\
\text { kepada guru/ } \\
\text { mata pelajaran }\end{array}$} \\
\hline 2 & Responden 2 & 3 & 4 & 3 & 4 & 3 & 17 & $T$ & \\
\hline 3 & Responden 3 & 2 & 3 & 2 & 3 & 2 & 12 & $S$ & \\
\hline 4 & Responden 4 & 4 & 3 & 3 & 4 & 4 & 18 & $T$ & \multirow{2}{*}{$\begin{array}{l}\text { 2. Keterlibatan } \\
\text { dalam }\end{array}$} \\
\hline 5 & Responden 5 & 2 & 3 & 2 & 3 & 2 & 12 & $S$ & \\
\hline
\end{tabular}




\begin{tabular}{|c|c|c|c|c|c|c|c|c|c|}
\hline & & & & & & & & & kegiatan \\
\hline 6 & Responden 6 & 3 & 3 & 2 & 3 & 3 & 14 & $S$ & \multirow{2}{*}{$\begin{array}{l}\text { 3. Mengulang } \\
\text { pelajaran }\end{array}$} \\
\hline 7 & Responden 7 & 2 & 3 & 3 & 2 & 2 & 12 & $S$ & \\
\hline 8 & Responden 8 & 2 & 3 & 2 & 2 & 3 & 12 & $S$ & \multirow{2}{*}{$\begin{array}{l}\text { 4. Perhatian } \\
\text { yang tinggi }\end{array}$} \\
\hline 9 & Responden 9 & 4 & 4 & 4 & 3 & 3 & 18 & $\mathrm{~T}$ & \\
\hline 10 & Responden 10 & 3 & 4 & 3 & 3 & 4 & 17 & $\mathrm{~T}$ & $\begin{array}{l}\text { 5. Tidak } \\
\text { mudah }\end{array}$ \\
\hline 11 & Responden 11 & 4 & 4 & 4 & 3 & 3 & 18 & $\mathrm{~T}$ & \multirow{10}{*}{$\begin{array}{c}\text { ST }: \text { Sangat } \\
\text { Tinggi } \\
\text { T : Tinggi } \\
\text { S : Sedang } \\
\text { R : Rendah } \\
\text { SR : Sangat } \\
\text { Rendah }\end{array}$} \\
\hline 12 & Responden 12 & 4 & 5 & 5 & 5 & 4 & 23 & ST & \\
\hline 13 & Responden 13 & 3 & 3 & 4 & 4 & 3 & 17 & $\mathrm{~T}$ & \\
\hline 14 & Responden 14 & 3 & 3 & 2 & 3 & 3 & 14 & $S$ & \\
\hline 15 & Responden 15 & 3 & 4 & 3 & 3 & 4 & 17 & $\mathrm{~T}$ & \\
\hline 16 & Responden 16 & 3 & 4 & 4 & 4 & 3 & 18 & $\mathrm{~T}$ & \\
\hline 17 & Responden 17 & 3 & 3 & 3 & 3 & 3 & 15 & $S$ & \\
\hline \multirow[t]{3}{*}{18} & Responden 18 & 2 & 3 & 2 & 3 & 3 & 13 & $S$ & \\
\hline & Jumlah & 53 & 62 & 54 & 59 & 56 & 284 & & \\
\hline & $\begin{array}{c}\text { Prosentase } \\
(\%)\end{array}$ & 58.89 & 68.89 & 60 & 65.56 & 62.22 & 63.11 & & \\
\hline
\end{tabular}

Tabel 4

Penilaian Minat Siswa dalam Pembelajaran Siklus 2

\begin{tabular}{|c|c|c|c|c|c|c|c|c|c|}
\hline \multirow{2}{*}{ No } & \multirow{2}{*}{ Responden } & \multicolumn{5}{|c|}{ Aspek Observasi } & \multirow{2}{*}{$\begin{array}{c}\text { Jumlah } \\
\text { Skor }\end{array}$} & \multirow{2}{*}{ Kategori } & \\
\hline & & 1 & 2 & 3 & 4 & 5 & & & \\
\hline 1 & Responden 1 & 4 & 4 & 4 & 4 & 3 & 19 & $\mathrm{~T}$ & \multirow{3}{*}{$\begin{array}{l}\text { 1. Ketertarikan } \\
\text { kepada guru/ } \\
\text { mata pelajaran }\end{array}$} \\
\hline 2 & Responden 2 & 5 & 5 & 4 & 5 & 4 & 23 & ST & \\
\hline 3 & Responden 3 & 3 & 4 & 4 & 4 & 4 & 19 & $\mathrm{~T}$ & \\
\hline 4 & Responden 4 & 5 & 5 & 5 & 5 & 5 & 25 & ST & \multirow{2}{*}{$\begin{array}{l}\text { 2. Keterlibatan } \\
\text { dalam } \\
\text { kegiatan }\end{array}$} \\
\hline 5 & Responden 5 & 4 & 4 & 4 & 4 & 4 & 20 & $\mathrm{~T}$ & \\
\hline 6 & Responden 6 & 5 & 5 & 4 & 4 & 4 & 22 & ST & \multirow{2}{*}{$\begin{array}{l}\text { 3. Mengulang } \\
\text { pelajaran }\end{array}$} \\
\hline 7 & Responden 7 & 5 & 5 & 5 & 5 & 5 & 25 & ST & \\
\hline 8 & Responden 8 & 5 & 5 & 5 & 4 & 4 & 23 & ST & \multirow{2}{*}{$\begin{array}{l}\text { 4. Perhatian } \\
\text { yang tinggi }\end{array}$} \\
\hline 9 & Responden 9 & 5 & 5 & 5 & 5 & 5 & 25 & ST & \\
\hline 10 & Responden 10 & 4 & 5 & 5 & 5 & 4 & 23 & ST & $\begin{array}{l}\text { 5. Tidak } \\
\text { mudah }\end{array}$ \\
\hline 11 & Responden 11 & 5 & 5 & 5 & 5 & 4 & 24 & ST & \multirow{6}{*}{ S : Sedang } \\
\hline 12 & Responden 12 & 5 & 5 & 5 & 5 & 5 & 25 & ST & \\
\hline 13 & Responden 13 & 5 & 5 & 5 & 5 & 5 & 25 & ST & \\
\hline 14 & Responden 14 & 5 & 5 & 5 & 5 & 4 & 24 & ST & \\
\hline 15 & Responden 15 & 5 & 5 & 5 & 5 & 4 & 24 & ST & \\
\hline 16 & Responden 16 & 5 & 5 & 5 & 4 & 4 & 23 & ST & \\
\hline
\end{tabular}


Volume 8 Nomor 1 Tahun 2020

\begin{tabular}{|c|c|c|c|c|c|c|c|c|c|}
\hline 17 & Responden 17 & 4 & 4 & 4 & 4 & 4 & 20 & $\mathrm{~T}$ & \multirow{4}{*}{$\begin{array}{c}\text { R : Rendah } \\
\text { SR : Sangat } \\
\text { Rendah }\end{array}$} \\
\hline 18 & Responden 18 & 4 & 5 & 5 & 4 & 4 & 22 & ST & \\
\hline & Jumlah & 83 & 86 & 84 & 82 & 76 & 411 & & \\
\hline & Prosentase (\%) & $\begin{array}{c}92.2 \\
2\end{array}$ & 95.56 & $\begin{array}{r}93 \\
33\end{array}$ & $\begin{array}{l}91 . \\
11\end{array}$ & $\begin{array}{r}84 . \\
44\end{array}$ & 91.33 & & \\
\hline
\end{tabular}

Pada prasiklus hasil ujian kompetensi belum semua siswa mencapai ketuntasan minimal yaitu nilai 70 . Ketuntasan klasikal hanya 22,22 \% Siswa yang mencapai ketuntasan minimal hanya 4, 14 siswa yang lain belum mencapai ketuntasan. Data ini menunjukkan hasil belajar siswa yang rendah. Yang belum mencapai ketuntasan minimal sebesar $77,78 \%$. Dokumen evaluasi prasiklus dapat dilihat pada tabel 6.

Pada Siklus 1, terdapat 3 siswa mendapat nilai dengan predikat sangat baik dengan prosentase $16,67 \%$, 4 siswa mendapat nilai dengan kategori baik dengan prosentase $22,22 \%, 1$ siswa mendapat nilai dengan kategori cukup dengan prosentase $5,55 \%$, dan masih 10 siswa yang mendapat nilai kurang dengan prosentase 55,56 \%. Ketuntasan klasikal sebesar 44,44\%, belum mencapai target ketuntasan penelitian sebesar $80 \%$ siswa yang tuntas. Dokumen evaluasi siklus 1 dapat dilihat di tabel 7.

Pada siklus 2, terdapat 5 siswa mendapat nilai dengan predikat sangat baik dengan prosentase 27,78 \%, 1 siswa mendapat nilai dengan kategori baik dengan prosentase 5,55 \%, 12 siswa mendapat nilai dengan kategori cukup dengan prosentase $66,67 \%$, dan 0 siswa yang mendapat nilai kurang dengan prosentase $0 \%$. Ketuntasan klasikal sebesar $100 \%$, sudah mencapai target ketuntasan penelitian sebesar $80 \%$. Dokumen evaluasi siklus 2, dapat dilihat di tabel 8 .

Tabel 6: Daftar Distribusi Nilai Prasiklus

\begin{tabular}{|c|c|c|c|c|}
\hline No. & $\begin{array}{l}\text { Rentang } \\
\text { Interval }\end{array}$ & Frekuensi & Prosentase & Predikat \\
\hline 1. & $91-100$ & 0 & $0 \%$ & Sangat Baik \\
\hline 2. & $81-90$ & 1 & $5,55 \%$ & Baik \\
\hline 3. & $70-80$ & 3 & $16,67 \%$ & Cukup \\
\hline 4. & $\mathrm{D}<70$ & 14 & $77,78 \%$ & Kurang \\
\hline & $\sum f$ & 18 & $100 \%$ & \\
\hline \multicolumn{2}{|c|}{ Siswa Tuntas } & 4 & $22,22 \%$ & \\
\hline \multicolumn{2}{|c|}{$\begin{array}{l}\text { Siswa Belum } \\
\text { Tuntas }\end{array}$} & 14 & $77.78 \%$ & \\
\hline
\end{tabular}

Tabel 7: Daftar Distribusi Nilai Siklus 1

\begin{tabular}{|c|c|c|c|l|}
\hline No. & $\begin{array}{c}\text { Rentang } \\
\text { Interval }\end{array}$ & Frekuensi & Prosentase & \multicolumn{1}{|c|}{ Predikat } \\
\hline 1. & $91-100$ & 3 & $16,67 \%$ & Sangat Baik \\
\hline 2. & $81-90$ & 4 & $22,22 \%$ & Baik \\
\hline
\end{tabular}




\begin{tabular}{|c|c|c|c|l|}
\hline 3. & $70-80$ & 1 & $5,55 \%$ & Cukup \\
\hline 4. & $\mathrm{D}<70$ & 10 & $55,56 \%$ & Kurang \\
\cline { 1 - 3 }$\sum$ & 18 & $100 \%$ & \\
\cline { 1 - 3 } Siswa Tuntas & 8 & $44,44 \%$ & \\
\cline { 1 - 3 } $\begin{array}{c}\text { Siswa Belum } \\
\text { Tuntas }\end{array}$ & 10 & $55,56 \%$ & \\
\hline
\end{tabular}

Tabel 8: Daftar Distribusi Nilai Siklus 2

\begin{tabular}{|c|c|c|c|c|}
\hline No. & $\begin{array}{l}\text { Rentang } \\
\text { Interval }\end{array}$ & Frekuensi & Prosentase & Predikat \\
\hline 1. & $91-100$ & 5 & $27,78 \%$ & Sangat Baik \\
\hline 2. & $81-90$ & 1 & $5,55 \%$ & Baik \\
\hline 3. & $70-80$ & 12 & $66,67 \%$ & Cukup \\
\hline 4. & $D<70$ & 0 & $0 \%$ & Kurang \\
\hline & $\sum f$ & 18 & $100 \%$ & \\
\hline \multicolumn{2}{|c|}{ Siswa Tuntas } & 18 & $100 \%$ & \\
\hline \multicolumn{2}{|c|}{$\begin{array}{c}\text { Siswa Belum } \\
\text { Tuntas }\end{array}$} & 0 & $0 \%$ & \\
\hline
\end{tabular}

\section{SIMPULAN}

Terdapat peningkatan minat dalam mengartikan sifat mustahil Allah setelah diberikan pembelajaran dengan model make a match pada siswa kelas III SD Negeri 1 Tegalharjo tahun 2017/2018 dari terdapat siswa yang masih berminat rendah pada prasiklus, pada siklus 2 sudah 100\% siswa memiliki minat pada rentang 16-20 dengan kategori tinggi.

Terdapat peningkatan hasil belajar KD 6.2 Mengartikan Sifat Mustahil Allah dengan model pembelajaran make a match $31,61 \%$ dari ketuntasan klasikal $\quad 16,67 \%$ dengan kategori kurang pada prasiklus, naik menjadi $100 \%$ dengan kategori sangat baik pada siklus 2 .

\section{DAFTAR PUSTAKA}

Ahmad Fauzi. 1999. Psikologi Umum . Bandung : Pustaka Setia.

Ali Imran. 1996. Belajar dan Pembelajaran. Jakarta : Dunia Pustaka Jaya Jakarta.

Ana Laila Soufia \& Zuchdi.2004. Jurnal Penelitian dan Evaluasi. Yogyakarta: UNY.

Aqib Zainal. 2014. Model-model, Media dan strategi Pembelajaran Kontekstual (Inovatif). Bandung: Yrama Widya.

Djamarah dan Aswan Zain. 2002. Psikologi Belajar. Jakarta : PT. Rineka Cipta. 
Gie, The Liang. 1998. Cara Belajar yang Efisien. Yogyakarta : Pusat Belajar IImu Berguna.

Iskandar. 2012. Panduan Penelitian Tindakan Kelas bagi Guru. Jakarta : Bestari Buana Murni .

Lie, Anita. 2008. Cooperative Learning. Jakarta : PT Grasindo.

Mihtahul Huda. 2013. Model-model Pengajaran dan Pembelajaran. Yogyakarta: Pustaka Pelajar.

Ngalimun. 2012. Strategi dan Model Pembelajaran. Banjarmasin : Aswaja Pressindo.

Slameto. 2003. Belajar dan Faktor-faktor yang Mempengaruhinya. Jakarta : Rineka Cipta.

Sudirman.2003. Pembentukan Minat. Jakarta:Pustaka Karya.

Sudjana. 2004. Dasar-Dasar Proses Belajar Mengajar. Bandung: Sinar Baru Algesindo.

Sumadi Suryabrata. 1998. Psikologi Kepribadian. Jakarta: Rajawali.

Sutrisno Hadi. (1994). Statistik. Yogyakarta : Andi.

Suyatno.2009. Menjelajah Pembelajaran Inofatif. Sidoarjo:Masmedia Buana Pusaka.

Wahab. 2007. Metode dan Model-Model Mengajar. Bandung:Alfabeta.

Winarno Surakhmad.1980. Pengantar Penelitian Ilmiah (Dasar, Metode, dan Teknik).Bandung : Tarsito.

Hosnan, M. (2014). Pendekatan Saintifik dan Kontekstual dalam Pembelajaran Abad 21. Bogor: Ghalia Indonesia. 